\title{
A Proposed Future Vision for Improving the Virtual Learning Culture in Jordanian Schools
}

\author{
Lina Kleaf AlQallab ${ }^{1} \&$ Mohammad Saleem Al-Zboon ${ }^{2}$ \\ ${ }^{1} \mathrm{PhD}$ Student, Foundations of Education, University of Jordan, Jordan \\ ${ }^{2}$ Faculty of Educational Sciences, University of Jordan, Jordan \\ Correspondence: Mohammad Saleem Al-Zboon, Profesor Faculty of Educational Sciences, University of Jordan. \\ E-mail: m.alzboon@ju.edu.jo
}

Received: January 25, 2018 Accepted: March 6, 2018 Online Published: March 19, 2018

doi:10.5539/mas.v12n4p13 URL: https://doi.org/10.5539/mas.v12n4p13

\begin{abstract}
The present study aimed to identify the future vision for developing the culture of virtual education in Jordanian schools by identifying the reality of the virtual education culture and the difficulties in applying this type of education.The study sample consisted of (2000) teachers and teachers representing all the directorates of education in Jordan, and were selected in the random stratified manner.The results showed that the reality of the virtual education culture in Jordanian schools from the point of view of the primary stage teachers in Jordan was high and that the difficulties facing virtual education in Jordan were high. Based on the results, the paper recommended to Bringing up people who accept the culture of change and adapt to it which shall enable them to seek achieving their ambitions and develop their potentials. and Promoting a culture that is based on a scientific methodology and employing people's mental skills and scientific methods to find practical solutions for societal problems. The vision's outlines include developing a personality that is capable to reach knowledge through using various sources of information.
\end{abstract}

Keywords: future vision, virtual learning culture, Jordanian schools

\section{Introduction}

Education is considered the most influential factor affecting human development. It should be noted that societies' success in making a keeping up with the changes associated with the information age depends on their success in the educational areas. Many people criticize the educational process as being slow in keeping up with the technological changes. They also criticize it for not employing the information and communications technology (ICT) software and devices. Decision makers can resolve such problems through making educational reforms that are based on the interaction between education, society and technology.

The field of education involves many approaches and philosophies. However, all of them are derived from the society's reality, ambitions, and aspirations. They are also derived from the changes associated with time and place. Educational philosophies emphasize the fact that the educational system must keep changing in response to the society's wants and needs that keep changing rapidly(Odeh and Al-,2018).

School is the educational intuition responsible for children's socialization and education through making them go through various educational stages. Therefore, there is an urgent need to have schools that can fulfill the society's requirements and provide suitable conditions for students provided to them from early age. Such conditions should enable students to practice the scientific methods in searching, and thinking. These conditions should enable them to acquire scientific skills in using and employing the recent technologies and adapt to them. Such schools are highly needed in the light of the technological advancements that have significantly increasing and entered the educational process. The learning process is not limited any more to the traditional method in which the teacher delivers the information to students directly and face to face. The learning process is not limited any more to the use of data show devices and power point slides. In fact, the learning process has been improving and started to include advanced technologies, such as computers, internet, programs, chat rooms, and virtual classrooms (Ali, 2001).

In order for schools to maintain their significant status in society, and achieve its mission, they must avoid being isolated or reactionary. Regarding isolation, schools should not establish barriers between themselves and actual 
life and reality. That is why modern schools avoid using rigid unchanging curricula which are mainly based on the spoon-feeding methods and include meaningless symbols and terms. Schools should consider themselves responsible for serving the community and bringing up the future generation. They are also responsible for keeping up with the changes and dominant culture of society. They should also teach theoretical knowledge and their applications. The major concerns of schools should be represented in developing students' personalities, and personal capabilities, and brining up human beings who are able to face life and its challenges, especially the ones associated with the age of globalism. Such concerns should include brining up human beings who are able to cope with the society and contribute effectively to it.

Schools should avoid being reactionary. That means that they shouldn't hold on to old fashioned methods. For instance, some school managements hold on to old-fashioned methods because they believe that old methods are better, authentic and more effective. Instead, schools should make a combination of good old methods and good new methods. They should always seek making renewals. They should always search for knowledge and information and explore it. They should always employ human resources effectively for solving problems that have been increasing rapidly (Zaher, 2005).

During the contemporary information age and the significant spread of computers and internet, people started to employ technological resources for improving the quality and effectiveness of education. In addition, such resources have been employed for solving the problems facing learners in traditional learning. Due to using such technology in educational fields, several expressions related to modern education have emerged. Such expressions include: e-learning and virtual learning. Technological resources have been employed in education to enable people to adapt to any change or challenge they might face in the future and keep up with the contemporary age of information. Schools achieve these goals through providing the society with graduates who are highly qualified. However, that requires providing a suitable educational environment. Such environment should employ the advanced digital technologies in designing a virtual reality for students. Such technologies should exist in the classrooms, and labs. Schools should also recruit well trained employees who seeks promoting an advanced educational culture that is derived from the traditional one (Myeong, 2005)

It is highly significant to employ virtual educational technologies. That is because employing such technology shall develop learners' self-learning capabilities himself which shall enable him to learn in accordance with his own capabilities and potential. Employing virtual educational technologies shall provide learners with practical experiences that shall stimulate their motivation, enhance their potentials, and develop their sense of innovation. Such experiences shall enable them to explore the practical reality. Therefore, virtual educational technologies shall participate in developing learners' personalities. Such technologies are considered technologies that have been introduced recently into the field of education. They are considered advanced technologies that can be used in classrooms and lecture halls. They have been spreading significantly in most of the scientific areas. For instance, many research and academic entities have built virtual learning environments to teach various curricula That is because virtual learning environments are suitable for teaching all subjects. For instance, employing such environments shall enable learners to become engaged with the learning process and interact effectively. Employing such environments shall enable learners to save information in their long-term memories and understand complex information in an easy and dynamic manner. That shall also enable learners to understand complex concepts visually (Xu, 2006).

Virtual learning is an integrated learning that is based on information technology (IT). In the beginning, virtual learning was used in classrooms and school labs. Later on, the first international conference about virtual learning was held in Denver in the United States of America in 1997. After that, a summit conference about virtual learning was held and the officials responsible for educational matters attended it. Through the latter conference, these officials emphasize the importance of virtual learning in making learners acquire the skills that are necessary to adapt with the future changes. These officials also suggest that such learning shall provide learners with many opportunities that were not available before (Ibrahim, 2011).

Virtual learning requires having a virtual environment that employs artificial intelligence and technological means. The virtual learning environment simulates the actual reality through using the visual imagination method. This method enables students to represent the actual reality, make it more attractive and interact with it. It should be noted that virtual learning is based on three pillars. The first pillar is interactivity. It means that leaner's can choose the information they are seeking and can participate in processing data leading them to produce useful information by themselves. The second pillar is cooperation. It mean that students can communicate and cooperate with the electronic mediator and their colleagues. The third pillar is experience. It means that learners can be engaged in their own learning process and participate in it (Al-Mahdi, 2008). 
Virtual learning is highly significant because it provides learners with virtual experiences that can serve as alternatives for the actual experiences that may be difficult or impossible to acquire. Such experiences may include walking into a factory that includes a nuclear reactor. That shall add entertainment and fun to the learning process and enable students to learn information through controlled experiences. Virtual learning enables learners to present scientific facts in three dimensional graphics. It narrows the gap between theoretical knowledge and its application. It enables students to learn skills and practice them instantly. Virtual learning also enables the officials responsible for educational matters to solve the problems related to the field of education. For instance, such learning enables them to imagine the problem, understand it, suggest solutions for it, and apply such solutions. It eliminates the temporal and spatial barriers that may prevent students from learning. It enables learners to avoid any risk resulting from conducting experiments. Such learning shall resolve the problem of having inadequate school labs' equipment and machines. It shall resolve the problems of teachers' inability to operate school labs' machines. It shall eliminate the need to maintain such machines in a regular manner. Such learning shall expand students' scientific imagination and develop their innovation skills. That is achieved through enabling them to experience anything that may come up on their minds. That is achieved through enabling them to make experiments in scientific fields that used to be considered un-experimental ones before, such as: math. Virtual learning shall simplify information and save it in students' long-term memories. Virtual learning shall enable students to avoid the risks associated with some dangerous experiments. Such dangerous experiments may include the ones that involve high voltage electricity and dangerous chemical materials (Nofal, 2010).

The Jordanian ministry of education seeks to develop the educational system and makes it based on knowledge economy. It also seeks to employ the information and communications technologies (ICT) in the Jordanian educational system and enable one to benefit himself and serve his community. Such goals are achieved through educating people in a way that combines between modernity and positive deep rooted traditions. In the World Economic Forum that was held in Jordan in 2003, King Abdullah II launched the Jordanian education initiative (JEI). The latter initiative aims at making educational reforms and employing ICT devices and software in the educational process. It aims at achieving that in order to enhance the quality of the provided education. The Jordanian government seeks to achieve a sustainable development in the field of education in order to enable Jordanians to participate in effectively in the knowledge economy locally, regionally and globally. His majesty King Abdullah ii has been always keen to improve and update the educational field and establish an educational environments that encourage students to innovate and excel. He has been always keen to provide all the advanced educational means that shall unlash and develop students' potentials. Such means are provided through developing the Jordanian educational infrastructure and providing buildings that are fully equipped with advanced educational means and modern labs. In addition, his majesty King Abdullah ii has been always keen to develop the quality of education through improving students' thinking and creativity skills. (The Jordanian ministry of education, 2015).

Based on the aforementioned, the following question may come up to mind:

(Does education today fulfill the requirements of the information age and the increasing demand for educated and skillful workforce?) In order for education to fulfill such demands and requirements, technology has been employed in the educational field and the views of the officials responsible for education have changed about such employment. In addition, changes have been occurring rapidly and technological advancements are developed constantly. Therefore, the educational culture must be re-constructed to keep up with the contemporary age and its associated changes.

\subsection{Statement of the Problem}

One of the researchers works in the Jordanian ministry of education. Due to the nature of her job, the latter researcher was able to notice that the dominant educational culture in schools is an old fashioned educational culture. For instance, the learning environments today still lack resources and do not motivate students towards increasing their academic achievement. Schools today do not keep up with dominant culture in today's society. To illustrate more, students still rely on the advanced ICT devices and software in their daily lives for playing games and communicating socially with others. They also enjoy using such devices and software and feel motivated to use it. However, an educational shock occurs when facing the traditional old-fashioned educational culture that is dominant at their schools. Therefore, they shall feel bored, and unmotivated to learn. Hence, the latter researcher believes that she must shed a light on this problem in the aim of spreading an interactive technological learning culture that simulates today's reality and keeps up with its associated changes. To be specific, the study shall propose a future vision for improving the virtual learning culture in Jordanian schools. The study shall provide answers for the following questions: 
Q.1)- What is the extent of availability of the virtual learning culture in Jordanian schools from the perspective of the teachers who teach at primary school sections in Jordan?

Q.2)- What are the difficulties facing the Jordanian educational system in the application of the virtual learning culture in Jordanian schools from the perspective of the teachers who teach at primary school sections in Jordan?

Q.3)- What is the appropriate future vision for improving the virtual learning culture in Jordanian schools?

\subsection{The Study'S Objectives}

The present study aimed at proposing an appropriate future vision for improving the virtual learning culture in Jordanian schools. Such a vision was proposed through identifying the extent of availability of the virtual learning culture in Jordanian schools from among teachers and students. That was identified from the perspective of the teachers who teach at primary school sections in Jordan. Such a vision was proposed through identifying the difficulties facing the Jordanian educational system in the application of the virtual learning culture in Jordanian schools from the perspective of the teachers who teach at primary school sections in Jordan.

\subsection{The Study'S Significance}

The present study is considered significant because it provides a future vision for improving the virtual learning culture in Jordanian schools. This proposed visions at fulfilling the educational needs of the societies. Such needs are based on knowledge economy, sustainable education and lifelong learning.

*As far as the researchers know, the present study is one of the few studies in Jordan that aimed at identifying the extent of availability of the virtual learning culture in Jordanian schools

-The present study provides effective contributions to the Jordanian ministry of education through providing it with useful results. Such results represent a feedback about the significance and availability of the virtual learning culture in Jordanian schools. Such results shall enable them to identify their duties

\subsection{The Theoretical and Operational Definitions}

The terms of the present study are defined below:

The operational definition of the future vision: It refers to a plan that involves several perceptions about the dominant educational culture in Jordanian schools in the future. This plan was set through coming up with the possible methods for improving the virtual learning culture in Jordanian schools and exploring, examining, and assessing these methods

Virtual learning: It refers to the learning process that is based on using electronic mediator to conduct a communication between teachers and learners. This process simulates the actual reality through using sounds, and three dimensional graphics (3D- graphics). This mediator enables learners to interact with these sounds and graphics and affect them through changing, developing or adjusting them (Ibrahim, 2011, p.33).

\subsection{The Study'S Limits}

The limits of the present study are:

1) - Thematic limits: The present study is limited to exploring the role of the Jordanian government in improving the virtual learning culture in Jordanian schools.

2) - Temporal limits: The present study was conducted during the first semester of the academic year 2017 / 2018.

3)- Spatial limits: The present study in the primary sections of Jordanian schools that are affiliated with the directorates of education.

4)- Human limits: The present study is limited to the teachers who teach at primary school sections in Jordan

\section{Previous Studies}

The researchers presented below some previous studies that concern the study's subject. They are arranged according to their chronological order from the oldest to the newest. They are also categorized into Arab and foreign studies:

\subsection{The Arab Studies}

Hasan (2013) aimed at identifying the effectiveness of the virtual learning environment and virtual factors in raising students' achievement motivation. That was done through adopting a descriptive experimental approach. A purposive sample was selected from 4th year students majoring in information technology at the faculty of education at Ain Shams University. The sample consists from 25 students. They fulfilled the required criteria, 
such as: having low motivation level, and being highly competent in using computers and internet. The instruments include: achievement motivation scale, a scale for identifying students' attitudes towards the virtual learning environment, and an achievement test for measuring knowledge related aspects after employing the virtual learning environment. The latter researcher used also an observation card for measuring skills- related aspects after employing the virtual learning environment. It was concluded that the three-dimensional virtual learning environment plays an effective role in raising students' achievement motivation level. That is because it provides students with flexibility in choosing the time and way of studying. It also enables students to handle responsibility and provide students with reinforcement constantly. In addition, it was concluded the three-dimensional virtual learning environment plays an effective role in raising students' academic achievement level. Such an environment encourages students to exert more efforts and seek achieving a high academic achievement level. In addition, it was concluded the three-dimensional virtual learning environment plays an effective role in increasing the interaction between students and the academic material leading them to have positive attitudes towards it.

Al-Agh'a (2015) aimed at exploring the effectiveness of employing the virtual reality technology in developing the visual thinking skills of 9th grade students in Gaza. An analytical descriptive approach was adopted to identify the visual learning skills in the engineering drawing unit. The latter researcher also adopted an experimental approach to identify the impact of the independent variable on the dependent one (i.e. the impact of the virtual reality technology on students' visual thinking skills). A sample of 80 female and male 9th grade students was selected randomly. It was concluded that there are statistically significant differences - at the significance level of $(0.05 \geq \alpha)$ - between the means of the experimental and control groups in the visual thinking post-test for the favor of the experimental group and attributed to the teaching method. It was concluded that the virtual reality technology plays an effective role in developing the visual thinking skills of 9th grade students in Gaza

Al-Turki (2016) aimed at identifying the impact of employing a virtual learning environment on the academic achievement, and thinking and IT skills of secondary school students enrolled in the schools of Saudi Arabia. The latter researcher selected a sample of 60 secondary school students enrolled in the schools of Saudi Arabia. The virtual learning environment was employed in biology. A semi-experimental approach was adopted through dividing the sample equally into control and experimental groups. The control group was taught through using the traditional learning method, whereas the experimental group was taught through using the virtual learning environment. The study used several instruments; virtual learning environment; learning management system and a written test to measure academic achievement and thinking and IT skills. It was concluded that the ones who were taught through using the virtual learning environment showed a higher academic achievement level and better thinking and information technology (IT) skills.

\subsection{Foreign Studies}

Ou, Tsai, Lin \& Hsu (2010) conducted a study in China. They aimed at exploring the effectiveness of virtual reality in teaching 3rd grade students about the water environment through simulating the actual water environment. Through using virtual reality technology, students were able to examine the animals and plants living in the water environment in a fun manner and easily. The experimental approach was adopted. The sample consists from 62 3rd grade students. It was concluded that the virtual reality technology plays an effective role in retrieving information, raising academic achievement level and improving critical thinking skills. It was concluded that such technology provides students with a better ability to explore things and interact with them

Hamrah (2011) aimed at exploring the relationship between virtual learning and the goals of the societies from seeking to obtain education from an existionalist perspective, specifically from Carl Jasper's existionalist perspective. A descriptive approach was adopted. It was concluded that Jasper believes that the societies of valuable cultural and historical heritage should have educational goals that participate in reviving their positive deep rooted traditions, customs and culture. Such societies must educate their members to be able to adapt to the future changes. Such societies should also enable their members to get a job. That can be achieved through virtual learning which keeps them up with today's age and simulates its dominant culture. It enables the society's members to develop and improve themselves. These things are goals that education seeks to achieve. However, it was concluded that virtual learning reduces the interaction between the teachers and students in the classroom and the school environment. Thus, it may participate in the disappearance of the society's old deep rooted culture. It weakens the process of transferring the cultural heritage from one generation to another.

Najad and Najad (2011) conducted a qualitative study that aimed at exploring the significance and feature of virtual learning and its principles and pillars. They also aimed at comparing it with the traditional learning, in 
terms of the education quality and effectiveness. They adopted a descriptive approach. It was concluded that virtual learning is a suitable alternative for traditional learning during the current age of information and internet revolution. Virtual learning is characterized with being flexible and effective. It is also able to achieve the highest satisfaction levels among students and teachers. It improves the quality of the provided education. It is available at any time and fulfills the students' needs. It is able to encourage students to learn and motivate them. It can keep up with their ambitions. It can resolve the problems that may prevent students from learning, such as: sickness, family conditions and living in remote areas. In other words, virtual learning eliminates the spatial and temporal barriers which may prevent students from learning. Traditional learning can't eliminate such barriers.

Smith (2014) aimed at exploring the effectiveness of virtual reality technology in teaching complex scientific terms for primary school students. The sample consists from 15 th grade students who are enrolled in the schools of Arizona at the United States of America. In addition, the latter researcher examined the observations of 30 teachers selected from Australia, Britain, and USA. The experimental approach was adopted. Pre-test and post-test forms were distributed to the sample. It was concluded that virtual learning plays an effective role in motivating students to learn, and improving their problem solving and critical thinking skills. It was concluded that such learning enables students to use technology more effectively

Toppin \&Toppin (2015) aimed at identifying the strengths of virtual learning and the challenges it can overcome in comparison to traditional learning. They also aimed at identifying the most suitable conditions for using it. An analytical descriptive approach was adopted. The latter researchers reviewed and examined several studies that concern the implementation of virtual learning in virtual schools in USA during the period 1999 - 2013. It was concluded that the demand on virtual learning has been increasing significantly due to its flexibility. Such flexibility makes it an effective alternative for traditional learning in the near future. It was concluded that most virtual schools are public schools. It was concluded that the companies funding virtual learning and schools have been increasing the amounts of money devoted for such funding. It was concluded that such learning is very suitable for the students who live in families that keep moving from one place to another, such as: the soldiers' families. It can significantly reduce the school dropout rates and provide educational services for the ones living in remote areas and experience difficulties in going to schools due to the far distance. It can also resolve the problem of having shortage in the educational means and resources in the schools located in rural areas. This kind of education can resolve the problem of having crowded schools and a high demand for educated workforce.

\subsection{Summary for the Aforementioned Studies and the Similarities and Differences Between Them and the Present Study}

It can be noticed that the aforementioned studies vary in terms of goals, variables andspatial limits. For instance, some of them deal with the significance, effectiveness and feature of virtual learning, such as the studies conducted by: Smith (2014), Najad and Najad (2011) and Toppin \&Toppin (2015). Other studies were concerned with the impact of virtual learning on academic achievement, motivation, and thinking skills, such as the studies conducted by: Ou, Tsai, Lin \& Hsu (2010), Hasan (2013), Al-Turki (2016), and Hamrah (2011). The latter study aimed at exploring the relationship between virtual learning and the societies' goals from seeking to obtain education from an existionalist perspective, specifically from Carl Jasper's perspective. The spatial limits of studies vary. Such limits include: USA, China, KSA, Egypt and Palestine.

It can be noticed that the aforementioned studies vary in terms of the approaches they adopt. Such approaches include: the descriptive and experimental approaches. They also vary in terms of the instruments they use. Such instruments include: achievement test, observation card and scales for identifying attitudes. Similar to some of the aforementioned studies, the present study adopted a developmental descriptive approach.

As for the contributions of the aforementioned studies, these studies participated in enriching the theoretical literature. These studies participated in guiding the researchers of the present study in term of expressing the study's problem, selecting the suitable methodology and following the suitable procedures and steps.

As for the things that distinguish the present study from the aforementioned studies, the present study is one of the few studies in Jordan that aimed at suggesting a future vision for improving the virtual learning culture in Jordanian schools from the perspective of the teachers who teach at primary school sections in Jordan.

\section{The Study's Approach}

The present study adopted a developmental descriptive approach as being the most suitable approach for fulfilling the study's objectives. This approach was adopted through using a questionnaire to collect the required data. 


\subsection{The Study'S Population}

The study's population consists from all the female and male teachers who teach at primary school sections in Jordan during the academic year 2017 / 2018. According to the statistics of the Jordanian ministry of education for the academic year 2017 / 2018, the study's population consists from56568 teachers.

\subsection{The Study'S Sample}

The study's sample consists from 2000 female and male teachers who teach at primary school sections in Jordan during the academic year 2017 / 2018. They were selected through using the random stratification method

\subsection{The Study'S Instrument}

The study's instrument was designed through reviewing the relevant theoretical studies that deal with the reality of the virtual learning culture in schools. Such studies include the ones conducted by: Najad and Najad (2011) and Smith (2014). The instrument - in its preliminary form - consists from 57 statements. Each statement is provided with several multiple choice items, which are: (Always, often, sometimes, a little, and rarely).

\subsection{The Instrument'S Validity}

The instrument was passed to 10 experts who are professors specialized in educational sciences and possess adequate experience in teaching at Jordanian universities. They were asked to provide their comments about the clarity and grammar of the statements and their relevancy to the things they aim to measure. The experts' comments and suggestions about the statements were taken into consideration. Thus, some statements were re-drafted. The statements that received the approval of $80 \%$ or more of the experts were approved and considered valid. All the statements received the approval of $80 \%$ or more of the experts. Therefore, all the statements were approved and valid. Thus, the instrument - in its final form - consists from 57 statements and the researchers did not delete any statement.

\subsection{The Study's Reliability}

In order to measure the study's reliability, a test-re-test method was used. That was done through distributing the questionnaire forms to an exploratory sample that consists from 40 male and female teachers. They were selected from outside the study's actual sample. The questionnaire forms were distributed again to the same members of the exploratory sample with having a time interval of two weeks. In order to measure the instrument's reliability, the Pearson correlation coefficient values were calculated. These values are presented in table (1) below:

Table 1 . The reliability coefficient values of the statements

\begin{tabular}{lll}
\hline No. & Aspect & Pearson correlation coefficient values \\
\hline 1 & Environment & 0.87 \\
2 & Teacher & 0.84 \\
3 & Student & 0.83 \\
4 & Difficulties & 0.82 \\
Total & & 0.84 \\
\hline
\end{tabular}

*The values are arranged according to their descending order

Based on table (1) above, it can be noticed that the total Pearson correlation coefficient value is 0.84

\subsection{Statistical Analysis Methods}

In order to answer the study's questions, the relevant statistical analysis methods were used. That is illustrated below:

1)- In order to answer the first question, arithmetic mean, standard deviation, levels and ranks were identified.

2)- In order to answer the second question, arithmetic mean, standard deviation, levels and ranks were identified.

The researchers used the equation listed below to classify means in order identify the extent of availability of the virtual learning culture in Jordanian schools from the perspective of the teachers who teach at primary school sections in Jordan. Such classification was used to identify the difficulties facing the Jordanian educational system in the application of the virtual learning culture in Jordanian schools from the perspective of the teachers who teach at primary school sections in Jordan.

(The maximum value of the alterative - the minimum value of the alterative) / the number of the scores 
$(5-1) / 3=1.33$

Therefore, the means are classified according to the following criteria:

Low means: $1-2.33$

Moderate means: $2.34-3.67$

High means: $3.68-5$

\section{Results and Discussion}

This part presents the study's results and discussion:

\subsection{Results of the First Question}

Q.1)- What is the extent of availability of the virtual learning culture in Jordanian schools from the perspective of the teachers who teach at primary school sections in Jordan?

Arithmetic mean, and standard deviation were calculated to identify the extent of availability of the virtual learning culture in Jordanian schools from the perspective of the teachers who teach at primary school sections in Jordan. They were also calculated for exploring each aspect of the study's aspects. These values are presented in tables 2, 3, 4 and 5 below:

Table 2. The arithmetic means, and standard deviations of the extent of availability of the virtual learning culture in Jordanian schools from the perspective of the teachers who teach at primary school sections in Jordan

\begin{tabular}{llllll}
\hline No. & Aspect & Arithmetic mean & Standard deviation & Rank & Level \\
\hline 3 & Environment & 3.99 & 0.51 & 1 & High \\
1 & Teacher & 3.84 & 0.87 & 2 & High \\
2 & Student & 3.51 & 0.63 & 3 & Moderate \\
\multicolumn{2}{l}{ Total } & 3.78 & 0.49 & High & \\
\hline
\end{tabular}

*The values are arranged according to their descending order

It can be noticed that the overall mean is 3.78 and the overall standard deviation is 0.49 . Such a mean indicates that the virtual learning culture in Jordanian schools is highly available from the perspective of the teachers who teach at primary school sections in Jordan. The values presented in table (2) are either high or moderate. For instance, the means are within the range of $3.99-3.51$. The environment aspect is ranked first due to having a mean of 3.99. The standard deviation of the latter aspect is 0.51 . The teacher related aspects are ranked second due to having a mean of 3.84 . The standard deviation of the latter aspects is 0.87 . As for the student-related aspects, they are ranked third due to having a mean of 3.51. The standard deviation of the latter aspects is 0.63 .

These results may be attributed to the following reasons:

Teachers believe that the virtual learning culture is available in Jordanian schools. For instance, most schools have computer labs and an internet connection. Most students have computers or smart phones. Teachers also possess computer skills in using computers and internet because they attended many training courses that were organized by the directorates of education. The ministry of education is keen to hold such courses in order to make educational reforms and employ information and communications technologies (ICT) in the educational process. It aims at achieving that in order to develop electronic education, achieve sustainable development in the field of education and promote lifelong learning

Student-related aspects show a moderate mean. That is attributed to the fact that employing virtual learning requires having special skills, capabilities and motivation to learn within students. Students should possess these qualities to be able to handle their own learning. This moderate value can be also attributed to the fact that students need to receive training courses about the way of using the electronic devices that serve as mediators for delivering, and receiving information. They must also receive training courses about the way of using the virtual learning programs.

As for the statements of each aspect, they are listed below:

1)- The environmental aspect

Arithmetic mean, standard deviation, levels and ranks were identified to identify the extent of availability of the virtual learning culture in the environments of Jordanian schools from the perspective of the teachers who teach 
at primary school sections in Jordan. These values are presented in table (3) below:

Table 3. The arithmetic mean, standard deviation, levels and ranks of the extent of availability of the virtual learning culture in the environments of Jordanian schools from the perspective of the teachers who teach at primary school sections in Jordan

\begin{tabular}{|c|c|c|c|c|c|}
\hline No. & Statement & $\begin{array}{l}\text { Arithmetic } \\
\text { mean }\end{array}$ & Standard deviation & Rank & Level \\
\hline 31 & $\begin{array}{l}\text { The virtual learning environment integrates various elements that } \\
\text { fulfill the needs of all learners }\end{array}$ & 4.19 & .79 & 1 & High \\
\hline 25 & $\begin{array}{l}\text { The virtual learning environment expands the learner's scientific } \\
\text { imagination in order to develop his sense of innovation. That is } \\
\text { achieved through enabling him to conduct experiments in any area } \\
\text { without being restricted to pre-prepared experiments in specific } \\
\text { areas }\end{array}$ & 4.07 & .73 & 2 & High \\
\hline 30 & $\begin{array}{l}\text { The virtual learning environment makes the learning process } \\
\text { entertaining and fun. It also enables learners to reach knowledge } \\
\text { through acquiring experiences by themselves }\end{array}$ & 4.05 & .89 & 3 & High \\
\hline 24 & $\begin{array}{l}\text { The virtual learning environment promotes interactivity through } \\
\text { promoting the principle of participatory }\end{array}$ & 4.04 & .81 & 4 & High \\
\hline 29 & $\begin{array}{l}\text { The virtual learning environment promotes an interaction between } \\
\text { society, education and technology }\end{array}$ & 4.03 & .81 & 5 & High \\
\hline 33 & $\begin{array}{l}\text { The virtual learning environment enables learners to achieve a } \\
\text { higher academic achievement level }\end{array}$ & 4.03 & .72 & 5 & High \\
\hline 26 & $\begin{array}{l}\text { The virtual learning environment enables learners to avoid the } \\
\text { risks resulting from dangerous experiments. It also enables them to } \\
\text { acquire virtual experiences that are alternative for actual } \\
\text { experiences that may be difficult or impossible to acquire }\end{array}$ & 4.02 & .78 & 6 & High \\
\hline 35 & $\begin{array}{l}\text { The virtual learning environment identifies the learner's training } \\
\text { needs and fulfills them }\end{array}$ & 4.01 & .72 & 7 & High \\
\hline 28 & $\begin{array}{l}\text { The virtual learning environment provides the learner with high } \\
\text { ability to control his own learning. It is also characterized with } \\
\text { being highly flexible }\end{array}$ & 3.95 & .80 & 8 & High \\
\hline 27 & $\begin{array}{l}\text { The virtual learning environment enables the leaner to conduct } \\
\text { experiments in scientific fields that were considered } \\
\text { un-experimental field before, such as: math }\end{array}$ & 3.95 & .81 & 8 & High \\
\hline 32 & $\begin{array}{l}\text { The virtual learning environment enables the learner to choose the } \\
\text { information he would like to know and can participate in } \\
\text { processing the data leading him to produce the information by } \\
\text { himself }\end{array}$ & 3.90 & .76 & 9 & High \\
\hline 34 & $\begin{array}{l}\text { The virtual learning environment employs a variety of learning } \\
\text { styles and methods, such as: the personalized and collective } \\
\text { learning methods }\end{array}$ & 3.89 & .74 & 10 & High \\
\hline 23 & $\begin{array}{l}\text { The virtual learning environment provides an integrated learning } \\
\text { environment that is appropriate for developing the learner's skills } \\
\text { and providing him with knowledge }\end{array}$ & 3.86 & .89 & 11 & High \\
\hline \multirow[t]{2}{*}{36} & $\begin{array}{l}\text { The virtual learning environment participates in developing the } \\
\text { academic material and turns it into an interactive visualized e-book }\end{array}$ & 3.85 & .81 & 12 & High \\
\hline & Total & 3.99 & .51 & & High \\
\hline
\end{tabular}

*The values are arranged according to their descending order

Based on the results of table (3), it can be noticed that the total mean of this aspect is 3.99 and the total standard deviation of this aspect is 0.51 . The means are within the range of $(4.19-3.85)$. All of these values are high. The mean of statement (31) (4.19)is ranked first. This mean is high. The standard deviation of the latter statement is .79. That latter statement states the following: (The virtual learning environment integrates various elements 
that fulfill the needs of all learners). That is attributed to the fact that traditional learning does not take into consideration the individual difference nor the learning patterns of each learner. However, traditional and virtual learning include the same stimuli. Traditional learning also focuses on the mental and cognitive aspects with neglecting the other aspects. Virtual learning also develops the learner's self-learning capabilities. Virtual learning takes into consideration the learner's potentials, capabilities and learning pattern. It enables the learner to manage his own learning by himself

The mean of statement (25) (4.07) is ranked second. This mean is high. The standard deviation of the latter statement is 0.73 . The latter statement states the following: (The virtual learning environment expands the learner's scientific imagination in order to develop his sense of innovation). That is achieved through enabling the learner to conduct experiments in any area without being restricted to pre-prepared experiments in specific areas. This result is attributed to the fact that adjusting and updating information are not available in traditional learning. It is also attributed to the fact that traditional learning neglects the critical thinking and creative skills. It is also because traditional learning is based on memorizing, and reciting information and using the passive spoon-feeding method without exerting any effort by the student to search for information or explore it. However, virtual learning provides a flexible interactive learning environment that promotes creativity and employs various types of knowledge resources. Such resources involve: visual, auditory and kinesthetic learning aids.

The mean of statement (23) (3.86) holds rank 11.This mean is high. The standard deviation of the latter statement is 0.89. The latter statement states the following: (The virtual learning environment provides an integrated learning environment that is appropriate for developing the learner's skills and providing him with knowledge). This result is attributed to the fact that visual learning narrows the gap between theoretical knowledge and its applications. Through virtual learning, the students can learn skills and are able to practice them. That can't be achieved through traditional learning.

The mean of statement (36) (3.86) is ranked last. This mean is high. The standard deviation of the latter statement is 3.85. The latter statement states the following: (The virtual learning environment participates in developing the academic material and turns it into an interactive visualized e-book). This result is attributed to the fact that virtual learning aims at changing the traditional style adopted in printing school curricula. It also aims at turning the learning environments into interactive learning environments that employ advanced technologies that can attract students and encourage them to learn. E-curricula enable student to interact with the academic material and make learning something entertaining. E-books also reduce the teachers' load and efforts. E-books have changed the teacher's role from being an information source and conveyor into a facilitator for the learning process and a guider for students. Students can have access to e-books at any time and place they choose. It is considered a suitable solution for the difficulty of gaining an access to the paper book.

\section{2)- The teachers-related aspects}

The arithmetic mean, standard deviation, levels and ranks were identified to identify the extent of availability of the virtual learning culture among teachers in Jordanian schools from the perspective of the teachers who teach at primary school sections in Jordan. These values are presented in table (4) below:

Table 4. The arithmetic mean, standard deviation, levels and ranks of the extent of availability of the virtual learning culture among teachers in Jordanian schools from the perspective of the teachers who teach at primary school sections in Jordan

\begin{tabular}{|c|c|c|c|c|c|}
\hline No. & Statement & $\begin{array}{l}\text { Arithmetic } \\
\text { mean }\end{array}$ & $\begin{array}{l}\text { Standard } \\
\text { deviation }\end{array}$ & Rank & Level \\
\hline 3 & $\begin{array}{l}\text { Developing the information and communications } \\
\text { technologies plays a significant role in improving the } \\
\text { educational process and the quality of the provided } \\
\text { education }\end{array}$ & 4.38 & .71 & 1 & High \\
\hline 2 & $\begin{array}{l}\text { Using the virtual learning technologies in schools } \\
\text { provides schools with an environment that supports } \\
\text { traditional learning }\end{array}$ & 4.34 & 3.06 & 2 & High \\
\hline 1 & $\begin{array}{l}\text { Providing the student with three-dimensional educational } \\
\text { experiences shall increase the effectiveness of education }\end{array}$ & 4.07 & .80 & 3 & High \\
\hline 5 & $\begin{array}{l}\text { Virtual learning aims to improve the cognitive, and } \\
\text { affective skills of students }\end{array}$ & 3.92 & 1.03 & 4 & High \\
\hline
\end{tabular}


$9 \quad$ I think that using virtual learning technology shall play an effective role in the learning-teaching process

Virtual learning technologies serve as appropriate means for providing the student with field training. Using such technologies shall narrow the gap between theoretical knowledge and its applications

6 I have the skills required for using virtual learning technologies. I am also able to use the virtual learning software and programs

7 I have e-texts or three-dimensional graphics that cover the academic material I teach

8 I have studies about the application of virtual learning in universities

Total

\subsection{7}

3.76

3.56

3.56

3.13

3.84
.91

.95

1.29

.87
$5 \quad$ High

6 High

7 Moderate

$7 \quad$ Moderate

$8 \quad$ Moderate

High

*The values are arranged according to their descending order

Based on the results of table (4), it can be noticed that the total mean of the teachers-related aspects is 3.84 . The total standard deviation of these aspects is 0.87 . The means are within the range of $(4.38-3.13)$. All of these values are either high or moderate. The mean of statement (3) (4.38) is ranked first. This mean is high. The standard deviation of the latter statement is.71. That latter statement states the following: (Developing the information and communications technologies plays a significant role in improving the educational process and the quality of the provided education). This result is attributed to the fact that virtual learning is associated with many problems. Such problems include its inability to fulfill the quality requirements of the information age. Such problems also include its inability to keep up with the massive developments made in the scientific fields. Such problems also include poor curricula whether such poorness is attributed to their scientific content or method of presenting information. The result of statement (3) may be attributed to the fact that the traditional educational method do not adopt mechanisms for updating the information of the curricula constantly to make them include the latest scientific knowledge. In addition, the traditional educational method do not adopt mechanisms for developing the student's thinking skills and expanding their imagination. Such method doesn't adopt mechanisms for training students to learn by themselves

The mean of statement (2) (4.34) is ranked second. This mean is high. The standard deviation of the latter statement is 3.06. That latter statement states the following: (Using the virtual learning technologies in schools provides schools with an environment that supports traditional learning). This result is attributed to the fact that the officials responsible for educational matters, especially the decision makers are afraid from the fact that virtual learning might become a threat against the survival of the traditional learning process. However, the decision makers who make decisions in the field of education aim to employ the virtual learning technology as a learning aid supporting the traditional learning methods. Such decision makers aim to employ this technology as an educational mean that overcomes the weaknesses of the traditional learning methods. They aim to apply virtual learning because it employs several technological methods and instruments and serves as a flexible educational mean that provides students with access to education at any time or place. Decision makers do not seek to replace traditional learning with virtual education. In fact, they aim to make them complementing one another in the aim of promoting the application of the self-learning principle, ensuring the survival of the traditional educational process and achieving professional development

The mean of statement (7) (3.56) is ranked seventh. This mean is moderate. The standard deviation of the latter statement is 5.27. That latter statement states the following: (I have e-texts or three-dimensional graphics that cover the academic material I teach). This result is attributed to the fact that educational system is still based on the traditional learning method. That latter method is still based on paper books and do not use technological methods and means. Therefore, the traditional learning system shall make teachers work in an inflexible educational system under the traditional official daily working hours. In such a system, teachers must work according to a specific teaching schedule in which each class starts a specific time. In such a system, the curriculum is stiffed with too much information. This moderate result is attributed to the fact that teachers are suffering from numerous duties assigned to them. Carrying out these duties consumes much time which shall prevent them from keeping up with the recent advanced technologies and their applications.

The mean of statement (8) (3.13) is ranked eighth. This mean is moderate. The standard deviation of the latter 
statement is 1.29. That latter statement states the following: (I have studies about the application of virtual learning in universities). This result is attributed to the fact that teachers do not have the research skills that enable them to develop themselves, solve problems and provide answers to the questions that may arise in any subject in classrooms. Teachers should identify their duties. Such duties include being researchers and experts in the teaching profession. They must have their own visions for developing themselves professionally, rather than following orders only. They should seek achieving professional growth and development and keep up constantly with the recent advanced technologies and means. They should also look ahead to the future and its associated changes. They must have expectation about the outcomes resulting from the changes made in the educational system.

3)- The students' related aspects

Arithmetic mean, standard deviation, levels and ranks were identified to identify the extent of availability of the virtual learning culture among students in Jordanian schools from the perspective of the teachers who teach at primary school sections in Jordan. Table (5) presents these values.

Table 5. The arithmetic mean, standard deviation, levels and ranks of the extent of availability of the virtual learning culture among students in Jordanian schools from the perspective of the teachers who teach at primary school sections in Jordan.

\begin{tabular}{|c|c|c|c|c|c|}
\hline No. & Statement & $\begin{array}{l}\text { Arithmetic } \\
\text { mean }\end{array}$ & $\begin{array}{l}\text { Standard } \\
\text { deviation }\end{array}$ & Rank & Level \\
\hline 22 & $\begin{array}{l}\text { Students believe that virtual learning participates in } \\
\text { improving the quality of the provided education. They } \\
\text { also believe that such learning enables them to play an } \\
\text { effective role in society and be engaged in social life. }\end{array}$ & 3.83 & .72 & 1 & High \\
\hline 10 & $\begin{array}{l}\text { Students are capable to search for specific information } \\
\text { available on the World Wide Web through using } \\
\text { electronic devices and obtain it }\end{array}$ & 3.78 & 1.04 & 2 & High \\
\hline 15 & $\begin{array}{l}\text { Students prefer to learn through the virtual learning } \\
\text { method as being an easy method to employ when having } \\
\text { shortage of resources }\end{array}$ & 3.70 & .96 & 3 & High \\
\hline 11 & $\begin{array}{l}\text { Students are capable to process, and saveinformation } \\
\text { through using information and communications } \\
\text { technology (ICT) devices }\end{array}$ & 3.64 & .94 & 4 & Moderate \\
\hline 14 & $\begin{array}{l}\text { Students prefer the virtual learning environment because } \\
\text { it suits their needs, capabilities and learning patterns. It } \\
\text { also enables them to choose the experiences they would } \\
\text { like to acquire }\end{array}$ & 3.63 & 1.02 & 5 & Moderate \\
\hline 20 & $\begin{array}{l}\text { Students believe that virtual learning enables them to be } \\
\text { qualified professionally and achieve sustainable } \\
\text { development in the field of education }\end{array}$ & 3.61 & 1.05 & 6 & Moderate \\
\hline 21 & $\begin{array}{l}\text { Virtual learning increases students' motivation to achieve } \\
\text { a higher academic achievement level. }\end{array}$ & 3.58 & 1.11 & 7 & Moderate \\
\hline 16 & $\begin{array}{l}\text { Students believe that virtual learning shall provide them } \\
\text { with more opportunities to communicate with the teacher } \\
\text { in comparison to the traditional learning }\end{array}$ & 3.47 & .90 & 8 & Moderate \\
\hline 19 & $\begin{array}{l}\text { Students interact with the virtual learning environment } \\
\text { through conducting experiments, and reaching } \\
\text { knowledge through experiences and exploring the actual } \\
\text { environment in an entertaining and easy manner }\end{array}$ & 3.46 & .94 & 9 & Moderate \\
\hline 17 & $\begin{array}{l}\text { Students have ICT devices and systems that enable them } \\
\text { to interact with the virtual learning environment }\end{array}$ & 3.41 & 1.10 & 10 & Moderate \\
\hline
\end{tabular}


Students accept the idea that virtual learning eliminates

13 any temporal or spatial barrier and expands their imagination

Students have the capability to use, analyze, and reconstruct information to produce knowledge by themselves. That is done the aim of solving problems, and carrying out activities and tasks

18

Students have capabilities to use virtual learning to conduct experiments and do various scientific projects

Total
3.26

3.25

3.11

3.52
1.18

11

Moderate

1.21

12 Moderate

1.09

13 Moderate

Moderate

*The values are arranged according to their descending order

Based on the results of table (5), it can be noticed that the total mean of the students-related aspects is 3.52 . The total standard deviation of these aspects is 0.63 . The means are within the range of $(3.83-3.11)$. All of these values are either high or moderate. The mean of statement (22) (3.83) is ranked first. This mean is high. The standard deviation of the latter statement is .72. That latter statement states the following: (Students believe that virtual learning participates in improving the quality of the provided education. They also believe that such learning enables them to play effective role in society and be engaged in social life). This result is attributed to the fact that virtual learning fulfills the educational needs of individuals and society. For instance, it is a flexible learning that is in agreement with the increasing and changing needs of society. Virtual learning enables one to keep up with the recent technology constantly. It also fulfills the requirements of today's age. It also enables one to develop himself, acquire new knowledge, and employ such knowledge for practicing skills that serve his interests and the society's interests. Virtual learning is not a channel for delivering information. In fact, it is a virtual learning place that competes traditional learning, especially among young people.

The mean of statement (10) (3.78) is ranked second. This mean is high. The standard deviation of the latter statement is 1.04.That latter statement states the following:(Students are capable to search for specific information available on the World Wide Web through using electronic devices and obtain it). This result is attributed to the fact that virtual learning doesn't aim at computerizing traditional learning. In fact, it aims at developing the learning methods and directing students towards searching for information by themselves and acquiring knowledge. That shall provide them with structured learning that shall enable them to achieve their goals and achieve success.

The mean of statement (12) (3.25) is ranked twelfth. This mean is low. The standard deviation of the latter statement is 1.21. That latter statement states the following: (Students have the capability to use, analyze, and reconstruct information to produce knowledge by themselves. That is done the aim of solving problems, and carrying out activities and tasks). This result is attributed to the shortage of training courses provided to students. It is also attributed to the fact that students are in need for training courses and learning about the way of using electronic devices and software. Such learning and training courses are needed to develop their skills, educate them, and improve their problem solving skills. Such learning and training courses are also needed to make them acquire certain practical skills, such as: searching for specific information, and developing, and exchanging it.

The mean of statement (18) (3.11) is ranked last. This mean is low. The standard deviation of the latter statement is 1.09. That latter statement states the following: (Students have capabilities to use virtual learning to conduct experiments and do various scientific projects). This result is attributed to the fact that traditional learning doesn't include mechanisms that enable students to imagine, create, innovate, explore things, apply knowledge, and conduct experiments. It is also because traditional learning doesn't employ project-based learning methods which promote creativity and a sense of leadership among students. Employing project-based learning methods shall also introduce much knowledge and teach students many skills. It shall also link such knowledge and skills with the actual reality and employ them to solve real life problems

\subsection{Results of the Second Question}

Q.2)- What are the difficulties facing the Jordanian educational system in the application of the virtual learning culture in Jordanian schools from the perspective of the teachers who teach at primary school sections in Jordan?

In order to answer the second question, arithmetic mean, standard deviation, levels and ranks were identified. Table (6) presents these value below 
Table 6. The arithmetic mean, standard deviation, levels and ranks of the difficulties facing the Jordanian educational system in the application of the virtual learning culture in Jordanian schools from the perspective of the teachers who teach at primary school sections in Jordan

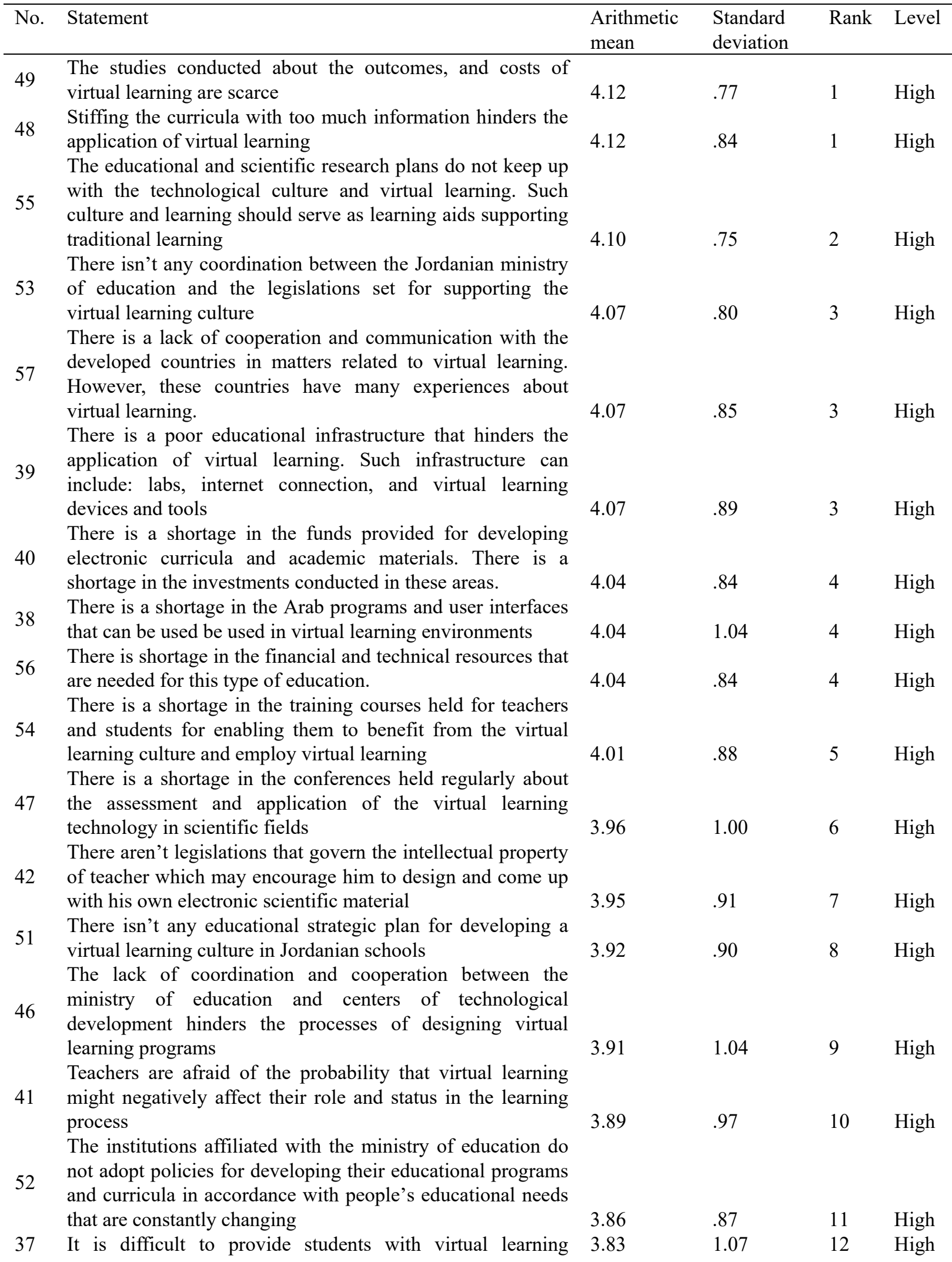


environment of low cost

There isn't Arab educational assessments conducted for

43 assessing the virtual learning environments after and during their employment in order to test the factors affecting the success of virtual learning

50

It is difficult to apply assessment methods and tools and keep tracking students" performance level

45 The Arab studies conducted about virtual learning are scarce Teachers do not play an effective role in motivating students

44 to benefit from the virtual reality programs that are available on the internet Total

\begin{tabular}{llll}
3.82 & .98 & 13 & High \\
& & & \\
3.81 & 1.00 & 14 & High \\
3.75 & .98 & 15 & High \\
& & & \\
3.74 & .98 & 15 & High \\
3.96 & .54 & & High \\
\hline
\end{tabular}

*The values are arranged according to their descending order

Based on the results of table (6), it can be noticed that the total mean of the amount of difficulties facing the Jordanian educational system in the application of the virtual learning culture is 3.96 which is a high value. The overall total standard deviation of the amount of these difficulties is 0.54 . The means are within the range of (4.12 - 3.74). All of these values are high. The mean of statement (49) (4.12) is ranked first. This mean is high. The standard deviation of the latter statement is 0.77 . That latter statement states the following: (The studies conducted about the outcomes, and costs of virtual learning are scarce). This result indicates that the most significant challenges and barriers hindering the process of promoting a virtual learning culture in Jordanian schools include: lack of adequate financial resources and funding. Such barriers can be resolved through conducting feasibility studies for identifying the actual cost of applying virtual learning. Such barriers can be resolved through varying the funding sources and making partnerships with the business, industrial and banking sectors and other governments in the field of virtual learning

The mean of statement (48) (4.12) is ranked first. This mean is high. The standard deviation of the latter statement is 0.83 . That latter statement states the following: (Stiffing the curricula with too much information shall hinder the application of virtual learning). This result is attributed to the fact that the ones who develop schools curricula in the traditional learning system are concerned with having much quantity of information in the curricula, rather than the having high quality. That represents a barrier that hinders the development and application of virtual learning. In order to overcome this barrier, curricula must be adjusted and their strengths must be identified. In addition, the unnecessary additional information must be deleted. Curricula should include the information that can enrich students' knowledge and improve their research skills. Curricula should seek achieving educational outcomes that can fulfill students' needs and achieve an interaction between society, education, and technology.

The mean of statement (44) (3.74) is ranked last. This mean is high. The standard deviation of the latter statement is 0.98 . That latter statement states the following: (Teachers do not play an effective role in motivating students to benefit from the virtual reality programs that are available on the internet).Such high mean indicates that teachers do not play effective role in motivating students to vary their learning sources and use virtual reality programs. However, teachers should play such a role in motivating students to search for information and raising their motivation to learn by themselves. In addition, teachers should play an effective role in encouraging students to use technology and communication networks. They should also play an effective role in enabling students to get opportunities in the future through reviewing and acquiring the information presented on the World Wide Web.

\subsection{Results of the Third Question}

Q.3)- What is the appropriate future vision for improving the virtual learning culture in Jordanian schools?

This vision that the researchers have proposed for improving the virtual learning culture in Jordanian schools is based on the fact that the information technology has become the basis of scientific and technological developments. The contemporary societies have started to claim for promoting a new educational and organizational ideologies. Societal changes must be associated with an educational changes through educating people in a way that shall enable them to adapt to the changes occurring today and will occur in the future. Such educational changes must employ people's potentials in solving their problems that have been increasing rapidly. Such educational changes can be made through proposing a future vision that enable people to look ahead to the future and its associated changes. 
Virtual learning technology is a learning pattern that has been recently invented. Virtual learning participates in raising the effectiveness of the educational process and overcoming the challenges that are facing societies. Such challenges include the ones associated with the increasing demand on education, scarcity of resources, high employment rates, and the inability of the educational outcomes to fulfill the requirements of the labor market requirements. In the light of the aforementioned, the vision that the researchers have proposed meets the requirements of the comprehensive development. It is also consistent with people's aspirations about the future. It is one of the positive solutions for resolving the crises that the educational field has been going through.

There are various forms for educational systems and the educational cultures associated with them. Each society has its own educational system and culture which suit its needs. The virtual learning culture is one of those educational cultures which the researchers hope that it will become a dominant culture in the future and part of reality.

The researchers listed below outlines for the vision they have proposed for improving the virtual learning culture in Jordanian schools:

1)- Bringing up people who accept the culture of change and adapt to it which shall enable them to seek achieving their ambitions and develop their potentials.

2)- Promoting a culture that is based on a scientific methodology and employing people's mental skills and scientific methods to find practical solutions for societal problems. The vision's outlines include developing a personality that is capable to reach knowledge through using various sources of information.

3)- Employing virtual leaning to raise the quality of the provided education and raise the effectiveness of the educational process in educational institutions. It should be employed to improve the outcomes of the educational process and connect them with the labor market needs and development requirements.

4)- Providing an internet connection in educational institutions to have an access to the World Wide Web. Such a connection should possess high quality and speed and facilitate students' access to the web.

5)- Increasing the opportunities of having access to the information sources.

6)- Providing students with virtual leaning programs in Arabic language to achieve the sought benefit and goals.

7)- Using various learning patterns as a part of an open and flexible educational system that provides students and teachers with adequate freedom. Such freedom shall enable them to innovate and show creativity.

8)- Supporting students' self-learning skills to enable them to continue their lifelong learning and training.

9)- Adjusting the school curricula to expand students' knowledge and provide them with advanced skills. Such skills should enable them to engage in the labor market easily. Such skills can be acquired through gaining experiences, applying theoretical knowledge and acquiring new patterns of knowledge, skills and information.

10)- Developing electronic forms for the paper-based curricula to serve as learning aids. E-curricula should be visualized interactive e-books that participate in transforming abstract experiences into tangible ones through which students can learn.

11)- Adopting effective strategies in intuitions to achieve the maximum benefit from technology and employ it in processes of production.

12)- Providing attention to the professional development programs targeting teachers. Such programs should provide teachers with the necessary skills for improving the virtual learning culture in Jordanian schools. Such programs should make teachers open minded and encourage them to look ahead to the future and its associated changes. Such programs should make them seek to develop themselves and expand their knowledge.

13)- Promoting the application of the self-learning principle and, sustainable, and professional development. The application of these things should become part of the dominant virtual learning culture in educational institutions among teachers and students.

14)- Adopting new assessment methods that are based on projects rather than being based on tests. Such methods should encourage students to search for information, show creativity, and develop their skills. . Such methods should involve students in solving the problems of their community.

\section{References}

Al-Agh'a, M. (2015). The effectiveness of virtual reality technology in developing the visual thinking skills among 9th grade students in Gaza. Unpublished MA Thesis. Islamic University, Palestine.

Ali, N. (2001). The Arab culture and information age. Kuwait: The national council for culture arts and literature 
Al-Mahdi, M. (2008). Virtual learning: Its philosophy, elements, and applicability. Alexandria, Al-Jame'a Al-Jadideh publishing and distribution house.

Al-Turki, O. (2016). The effectiveness of using amodel based on learning in a virtual environment in developing students' academic achievement, and thinking and IT skills among the secondary school students in Riyadh. Mu'tah Journal for Research and Studies - Humanitarian and Social Sciences, 31(5), 67-118.

Hamrah, S. (2011). Investigating the Relationship Between Virtual Education and Social Aims of Education From the viewpoint of Existence Philosophy with an Emphasis on Jaspers Thoughts. Procedia Social and Behavioral Sciences, 29, 1750-1758.

Hasan, M. (2013). The effectiveness of employing virtual learning environments and virtual factors in raising students' achievement motivation. Educational technology - Studies and research - Egypt, January, 2013, 309-333

Ibrahim, A. (2011). Libraries and learning in virtual environments. Alexandria, Al-Wafa' ledonay publishing and distribution house. Islamic Azad University, Iran.

Myeong, K. (2005). Relations on Adopting Immersive Virtual Reality in college Science Students Perception of Learning Environment. Book of the 3rd international conference on Multimedia and Information and communication Technologies in Education.

Nejad, M., \& Nejad, E. (2011). Virtual Education and its Importance as a New Method in Educational System. International Journal of Computer Science and Information Security.

Nofal, K. (2010). Virtual reality technology and its practical applications, Amman: Al-Manahej publishing and distribution house.

Odeh,T. and AlZboon,M. (2018). The Extent of Practicing Social Interaction Skills by Jordanian Elementary School Students in accordance with Carl Orff's Approach to Music Education. Modern Applied Scince, 12(3), 95-104.

Ou, K., Tsai, W., Lin, Y., \& Hsu, C. (2010). An Instructional Design Using the Virtual Ecological Pond for Science Education in Elementary Schools. Education Technology System, 38(4), 385-406.

Smith, T. (2014). Elementary Science Instruction: Examining a Virtual Environment for Evidence of Learning, Engagements and 21st Century Competencies. Education Sciences Western Illinois University, 4, 122-138.

The Jordanian ministry of education. (2015). Teaching and assessment strategies, Amman, Jordan.

Toppin, I., \& Toppin, S. (2015). Virtual Schools: The Changing Landscape of K-12 Education in the USA. Educ Inf Technol, 21, 1571-1581.

Xu, G. (2006). Virtual Reality Does Simulation for Nuclear Power.The American Nuclear Society's 14th Biennial Topical Meeting of the Radiation Protection and Shielding Division, New Mexico USA April 3-6, 2006, 449-451.

Zaher, A. (2005). A strategic plan for developing universities' educational systems through using electronic educational technology, Conference on the development of the Arab universities' performance level in accordance with the standards total quality and accreditation, 18-19 December, 2005. University Education Development Center in Ain Shams University.

\section{Copyrights}

Copyright for this article is retained by the author(s), with first publication rights granted to the journal.

This is an open-access article distributed under the terms and conditions of the Creative Commons Attribution license (http://creativecommons.org/licenses/by/4.0/). 